\title{
Frontal placement of subdural drain for subdural hemorrhage: A single center experience.
}

\author{
Mohammad Alif Yunus*, Mohd Asrol Hafizi Ab Majid, Arman Muhammad Nor, Nujaimin Udin \\ Neurosurgery Unit, Hospital Sultanah Nur Zahirah, Kuala Terengganu, Malaysia
}

\begin{abstract}
Placing a drain following evacuation of Chronic Subdural Hemorrhage (CSDH) has beneficial outcome for patients. The placement of the drain's tip however is debatable as it has different rationale among neurosurgeons.

Objective: The objective is to see whether the outcome is satisfactory by putting the tip of the drain at the frontal region of the sub dural space.

Methodology: We retrospectively studied all patients who had CSDH underwent surgery in our center between January 2013 to December 2016. A total of 34 patients with CSDH underwent drilling of one burr hole and irrigation of CSDH. Silicone catheter placed in the sub dural space and the tip of the drain in the frontal region. We measured the SDH volume reduction and volume of pneumocranium post operatively as our outcomes of the study.

Results: The mean reduction of SDH volume after surgery is 8.11 cc $(73 \%)$, while the mean volume of pneumocranium post SDH drainage is $1.58 \mathrm{cc}$ with a range of $0 \mathrm{cc}$ to $9 \mathrm{cc}$. The mean Global Outcome Score is $\mathbf{2 . 8 5}$ and the recurrence, which need re-operation are 2 cases $(6 \%)$.

Conclusion: The retrospective case series shows a good potential outcome based on the reduction of SDH volume after surgery. A proper randomized trial is needed to determine the efficacy of the frontal placement of the subdural catheter for a comparable outcome.
\end{abstract}

Keywords: Chronic sub dural hemorrhage, sub dural drain, Surgery, Intracranial pressure.

Accepted on March 01, 2019

\section{Introduction}

Chronic Subdural Hemorrhage $(\mathrm{CSDH})$ is a collection of liquefied blood underneath the Dura matter which has high incidence in population above 70 years old and after 70 years of age the incidence is $8 \cdot 2 / 100,000 /$ year. Hence, as the population ages, the prevalence is anticipated to increase. CSDH often present weeks or months after the first bleed, as the initial hematoma liquefies, it expands. The increase of volume may result in increased in intracranial pressure and subsequent neurological complications [1-3]. CSDH is a profound cause of morbidity and mortality in elderly.

Spontaneous resolution can occur, although surgical evacuation is warranted in most cases, in which patients whom deteriorate [4]. There are several surgical methods for evacuation of CSDH, and the benefit of placing drain postoperatively was confirmed in a recent meta-analysis. However, there were conflicting outcomes regarding in-situ placement of the drains. Our study is to review the outcome of CSDH evacuation in which the tip of the drain is placed at the frontal area, based on the volume of the CSDH post-operatively. We also measure the volume of pneumocranium postoperatively as it's one of the factors that cause re-accumulation of fluid in the sub-dural space after evacuation of the CSDH $[5,6]$.

\section{Methodology}

We retrospectively studied total of 34 patients with Chronic Subdural Haemorrhage diagnosed by CT scan (Figure 1), that were treated surgically in our center between January 2013 to December 2016. All patients underwent drilling of one burr hole and irrigation of the $\mathrm{CSDH}$, followed postoperatively by closed system drainage using silicone catheter size 8 Fr [7-9]. The position of the tip of the catheter was placed in the frontal region. CT scan brain was done after day 2-3 post operation and volume of the $\mathrm{CSDH}$ pre and post-operative were calculated as

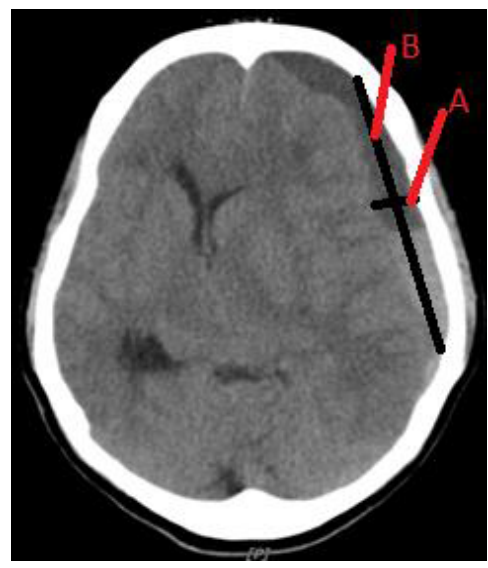

Figure 1. CT Brain Chronic Subdural Hemorrhage. 
Citation: Yunus MA, Majid MSHA, Nor AM, et al. Frontal placement of subdural drain for subdural hemorrhage: A single center experience. $J$ Trauma Crit Care. 2019;3(1):12-4

well as documentation of the post-operative pneumocranium volume. Both results were compared as our primary outcome and secondary [10,11] (Figures 2 and 3 ).

Volume calculation formula: $\frac{A \times B \times C}{2}$

A: Longest axis on CT axial view

$\mathrm{B}$ : Longest axis perpendicular to $\mathrm{A}$

$\mathrm{C}$ : Height on coronal view

\section{Results}

Baseline demographic data are shown in Table 1, which display the mean age for CSDH patient underwent operation were 68.3 years old and male patients are more predominant (73.5\%).

The primary outcome in Table 2 illustrates the mean reduction of SDH volume after surgery is $8.11 \mathrm{cc}(73 \%)$. The number of recurrence, which patients had to go for another operation, is 2 out of 34 patients.

The secondary outcome in Table 3 demonstrate the mean volume of pneumocranium post SDH drainage is $1.58 \mathrm{cc}$ with a range of $0 \mathrm{cc}$ to $9 \mathrm{cc}$. The mean Global Outcome Score is 2.85 and the recurrence, which need re-operation are 2 cases $(6 \%)$.

\section{Discussion and Conclusion}

It is logically understandable that fluid and air will follow the

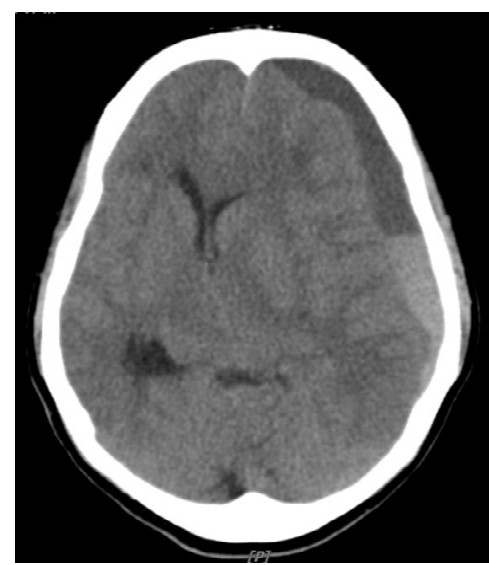

Figure 2. CT Brain Pre Burr hole and drainage.

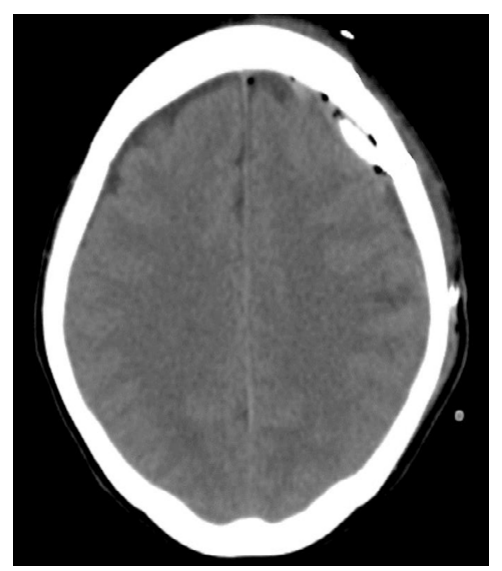

Figure 3. CT Brain Post Burr hole and drainage.
Table 1. Baseline demographic data.

\begin{tabular}{|c|c|c|}
\hline Characteristic & \multicolumn{2}{|c|}{$\mathbf{N = 3 4}$} \\
\hline Age & Mean (S.D) & $68.3(14.01)$ \\
\hline Gender & Male (\%) & $25(73.5)$ \\
\hline & Female (\%) & $9(26.5)$ \\
\hline Mean GCS & & 12 \\
\hline
\end{tabular}

Table 2. Reduction of SDH volume after surgery.

\begin{tabular}{|c|c|c|c|}
\hline & $\begin{array}{c}\text { SDH Thickness } \\
\text { Reduction } \mathbf{( c m )}\end{array}$ & $\begin{array}{c}\text { SDH Volume } \\
\text { Reduction } \mathbf{( c c )}\end{array}$ & $\begin{array}{c}\text { Percentage of Volume } \\
\text { Reduction (\%) }\end{array}$ \\
\hline Mean & 1.51 & 8.11 & $73 \%$ \\
\hline Std Deviation & 1.09 & 3.73 & 22.18 \\
\hline
\end{tabular}

Table 3. Volume of pneumocranium after surgery.

\begin{tabular}{|c|c|}
\hline & Volume of Pneumocranium Postoperative (cc) \\
\hline Mean & 1.58 \\
\hline Std. Deviation & 2.06 \\
\hline Range & $0-9$ \\
\hline
\end{tabular}

direction of gravity in a close space. In brain however it's a debatable condition. As shown in previous study by Nagagutchi et al. [2] in a retrospective study of 63 patients, frontal placement of SDH drain has the least recurrence rate $(5 \%)$ compared to other position placement of catheter.

In our study also, it shows a good outcome based on the volume of SDH reduction as well as the volume of pneumocranium left postoperatively. This is possibly because air will accumulate over the frontal region and placement of the catheter's tip at frontal region will help to drain the air out from the brain cavity. Thus, it enable brain parenchymal to fill in the void, and prevent fluid or blood to replace the space. The study however, is not a comparative study, and the data is taken retrospectively. The data outcome is not comparable and we could not conclude that the frontal placement of CSDH drain is the best compared to other position of drain placement. It's however, based on our opinion, produce desirable outcome in term of volume of SDH reduction and pneumocranium left postoperatively.

As a conclusion, a proper randomized trial is needed to determine the efficacy of the frontal placement of the subdural catheter, the retrospective case series shown a good potential outcome. This is essential to look at a more comparable out-come of placement of CSDH drain postoperatively.

\section{References}

1. Brennan PM, Kolias AG, Joannides AJ, et al. Management and Outcome For Patients With Chronic Subdural Hematoma: A prospective, Multicenter, Observational Cohort Study in The United Kingdom. J Neurosurg. 2016;127(4):732-9.

2. Nakaguchi H, Tanishima T, Yoshimasu N. Relationship Between Drainage Catheter Location And Postoperative Recurrence of Chronic Subdural Hematoma After BurrHole Irrigation And Closed System Drainage. J Neurosurg. 2000;93(5):791-5.

3. Sivaraju L, Moorthy RK, Jeyaseelan V, et al. Routine Placement of Subdural Drain After Burrhole Evacuation of Chronic Subdural Hematoma. Neurosurg Rev. 2018;41(1):165-71. 
4. Alcalá-Cerra G, Young AM, Moscote-Salazar LR, et al. Efficacy and safety of subdural drains after burr-hole evacuation of chronic subdural hematomas: systematic review. World Neurosurg. 2014;82(6):1148-57.

5. Soleman J, Kamenova M, Lutz K, et al. Drain Insertion in Chronic Subdural Hematoma: An International Survey of Practive. World Neurosurg. 2017;104:528-36.

6. Foelholm R, Waltimo O. Epidemiology of chronic subdural haematoma. Acta Neurochir (Wien). 1975;32(3-4):247-50.

7. Adhiyaman V, Asghar M, Ganeshram KN, et al. Chronic subdural haematoma in the elderly. Postgrad Med J. 2002;78(916):71-5.

8. Jones S, Kafetz K. A prospective study of chronic subdural haematomas in elderly patients. Age Ageing. 1999;28(6):519-21.

9. Smely C, Madlinger A, Scheremet R. Chronic subdural haematoma-a comparison of two different treatment modalities. Acta Neurochir (Wien) 1997;139(9):818-26.
10. Wakai S, Hashimoto K, Watanabe N, et al. Efficacy of closed system drainage in treating chronic subdural hematoma: a prospective comparative study. Neurosurgery. 26:771-3.

11. Smyth H, Livingston K. Ventricular infusion in the operative management of subdural hematoma, in Morley $\mathrm{T}$ (ed): Current Controversies in Neurosurgery. Philadelphia: WB Saunders, 1976;566-71.

\section{*Correspondence to:}

Mohammad Alif Yunus

Neurosurgery Unit

Hospital Sultanah Nur Zahirah

Kuala Terengganu

Malaysia

Tel: +60199057358

E-mail: malifyunus@yahoo.com 